PSICOLOGI A SOCIAL

\title{
A fenomenologia de Husserl no contexto da psicologia na virada para o século XX
}

\section{Husserl's phenomenology in the context of psychology at the turn of the twentieth century}

\section{La fenomenología de Husserl en el contexto de la psicología a la vuelta del siglo $X X$}

\section{Sávio Passafaro Peres*}

Pontifícia Universidade Católica de São Paulo - PUC-São Paulo, São Paulo, São Paulo, Brasil

\begin{abstract}
RESUMO
Neste artigo buscamos esclarecer como a fenomenologia de Husserl situa-se no contexto da psicologia na passagem para o século XX. Focamos especialmente na obra Investigações Lógicas, que marca a virada de Husserl à fenomenologia. Inicialmente, examinamos o surgimento da Psicologia Experimental na Alemanha para, posteriormente, examinarmos a influência que Husserl exerceu em algumas dessas escolas na primeira década do século XX e, em particular, nas escolas de Würzburg, Göttingen, Berlim e Munique. Constatamos que a fenomenologia de Investigações Lógicas foi recebida como uma forma de psicologia descritiva, cujo intuito seria a preparação conceitual para a elaboração de uma psicologia empírica.
\end{abstract}

Palavras-chave: fenomenologia, psicologia fenomenológica, história da psicologia.

\begin{abstract}
In this article we aim to clarify how Husserl's phenomenology is situated in the context of psychology at the turn of the twentieth century. We focus especially on the work Logical Investigations, which marks the breaking of Husserl to the phenomenology. Initially, we examine the emergence of experimental psychology in Germany. Then we examine the influence of Husserl in various schools of psychology in the first decade of the twentieth century, particularly in schools of Würzburg, Göttingen, Berlim and Munich. It is observed that the phenomenology of Logical Investigations was received as a form of descriptive psychology, whose aim would be the conceptual preparation for the development of an empirical psychology.
\end{abstract}

Keywords: phenomenology, phenomenological psychology, history of psychology.

\section{RESUMEN}

En este artículo nos proponemos aclarar cómo la fenomenología de Husserl se sitúa en el contexto de la psicología a la vuelta del siglo XX. Nos centramos especialmente en las Investigaciones Lógicas de trabajo, ya que esto marca la ruptura de la fenomenología de Husserl. Inicialmente, se 
examina el surgimiento de la psicología experimental en Alemania. Después se examina la influencia de Husserl en diversas escuelas de psicología en la primera década del siglo $\mathrm{XX}$, sobre todo en las escuelas de Würzburg, Gotinga, Berlín y Munich. Se observa que la fenomenología de Investigaciones lógicas fue recibido como una forma de psicología descriptiva, cuyo objetivo sería la preparación conceptual para el desarrollo de una psicología empírica.

Palabras-claves: fenomenología, psicología fenomenológica, historia de la psicología.

\section{I ntrodução}

É comum entre os historiadores da Psicologia afirmar que o ano de 1879 marca o início oficial da psicologia como disciplina experimental e autônoma, em virtude da fundação por Wilhelm Wundt, em Leipzig, do laboratório de pesquisas psicológicas. Embora a data seja problemática por uma série de razões (Smith, 2012), ela serve como marco do início de uma forte difusão da psicologia experimental. Com sua inauguração, concretiza-se um plano já delineado por Wundt em 1874 na sua obra Princípios de psicologia fisiológica (Grundzüge der physiologischen Psychologie), na qual ele traçou as hipóteses e diretrizes que haveriam de possibilitar e ocasionar um grande número de experimentos, criando um extenso e complexo programa de pesquisa. Essas pesquisas, que foram realizadas em seu laboratório majoritariamente por seus estudantes e orientandos, logo se avolumaram e exigiram para si um periódico temático, capaz de fazer justiça à especificidade do material. Assim, em 1881, Wundt fundou os Estudos Filosóficos (Philosophische Studien). Desde então, a psicologia experimental se difundiu rapidamente.

O uso do método experimental para a abordagem da consciência, que havia sido por tanto tempo dado como inviável, é retomado com força crescente. Em 1885, Hermann Ebbinghaus (1850-1909) publica sua obra Sobre a Memória (Über das Gedächtnis), na qual ele descreve os resultados experimentais obtidos em suas investigações acerca dos processos da memória e da aprendizagem. Nesse mesmo ano, Ebbinghaus torna-se professor assistente da Universidade de Berlim, onde funda o instituto de psicologia e lança, em 1890, a Revista psicológica e fisiológica dos órgãos dos sentidos (Zeitschrift für Physiologie und Psychologie der Sinnesorgane). Enquanto isso, um discípulo de Wundt, Georg Elias Müller (1850-1934) inaugura no ano de 1887, em Göttingen, outro importante centro alemão de psicologia experimental. Em 1894, a cobiçada cadeira de filosofia em Berlim, antes ocupada por Ebbinghaus, passa a ser ocupada pelo psicólogo Karl Stumpf (1848-1936), um dos mais notórios membros da escola de Brentano (1838-1917). Stumpf supervisiona Husserl em sua tese de habilitação e conduz, à mão de ferro, o instituto de 
psicologia de Berlim, onde florescerá, sobre sua tutoria, a psicologia da Gestalt.

Wundt (Leipzig), Ebbinghaus (Berlim), Stumpf (Berlim), G. E. Müller (Göttingen) e Külpe (1862-1915) (Würzburg) são considerados os pioneiros da psicologia científico-experimental na Alemanha, que terá um crescimento vertiginoso, ocupando cada vez mais espaço dentro das faculdades de filosofia. Em 1892, das 39 cadeiras de filosofia existentes na Alemanha, três eram preenchidas por psicólogos experimentais. Das 42 cadeiras em 1900, seis delas eram ocupadas por psicólogos experimentais. Em 1913, a situação era tal que os psicólogos já ocupavam dez cadeiras de antigos filósofos, ou seja, um quarto das cadeiras disponíveis nos departamentos de filosofia. Destas dez cadeiras, sete foram ocupadas por estudantes de primeira ou segunda geração de Wundt. Essa situação refletia-se também no número de periódicos dedicados à psicologia, os quais, em 1925, já somavam 59 (Kusch, 1995).

Essa rápida expansão da psicologia, longe de ser uma expansão progressiva e linear, ocorreu em meio a calorosas controvérsias, não apenas entre os psicólogos experimentais, mas, também, destes com os "filósofos puros", acerca do objeto e métodos da Psicologia. Muitos filósofos, vendo suas cadeiras serem tomadas por psicólogos, empenharam-se em defender a filosofia, mostrando as limitações da Psicologia Experimental.

A situação chegou a tal ponto que o plano das ideias não foi suficiente e, como poucas vezes na história, os filósofos se uniram politicamente. Em 1913, Natorp (1854-1924), Husserl (1959-1938), Rickert (1863-1936), Windelband (1848-1915) e outros elaboraram um manifesto defendendo a separação dos departamentos de psicologia e filosofia, recolhendo 107 assinaturas de filósofos da Áustria, Suíça e Alemanha e divulgando-o em todas as universidades de língua alemã. Segundo autores como Kusch (1995, p.186) e Araújo (2013), ao fazer isso, eles seguiram uma ideia que Husserl tinha sugerido a Natorp no início de 1911, ou seja, a de fundarem algum tipo de "união de professores" (Professorengewerkschaft) contra a ameaça da psicologia experimental.

O conflito institucional refletia alguns dos problemas teóricos: Quais são os domínios científicos e como delimitá-los? Qual a delimitação do objeto da Psicologia? Qual a relação entre a Psicologia e a Lógica, a Teoria do Conhecimento e as Ciências Naturais? Como abordar a consciência humana? Pela introspecção? Pelo método experimentalindutivo? Pelo método transcendental?

As respostas a essas questões geraram importantes controvérsias dentro das Faculdades de Filosofia alemãs. Dilthey (1833-1911), Husserl (1959-1938), Wundt(1932-1920), Ebbinghaus(1850-1909), Stumpf (1848-1936), Külpe (1862-1915), Theodor Lipps (18511914), todos eles ofereceram respostas a tais problemas e 
participaram de acirradas disputas. Apesar das várias divergências pontuais, é possível, entretanto, identificar duas grandes 'escolas' de Psicologia, as quais, em um primeiro momento, exerceram influência em Husserl. A primeira é aquela iniciada por Wundt e a segunda é aquela iniciada por Brentano.

É sabido que Husserl começou sua carreira na filosofia como discípulo de Brentano. Husserl, logo após ter terminado o seu doutorado em matemática, assistiu em Viena às preleções de Brentano, entre os anos de 1884 e 1886. Brentano foi decisivo por ter chamado a atenção de Husserl para a ideia de que a Psicologia deve ser basicamente uma análise da intencionalidade da consciência (Husserl, 1925/1962).

A influência que Wundt exerceu em Husserl é menos conhecida (Husserl, 1925/1962). Husserl, durante o tempo em que era estudante de matemática em Leipzig, assistiu às preleções de Wundt, de quem Husserl encontrou o critério para a delimitação do domínio da Psicologia: o fluxo instável de vivências ${ }^{1}$.

\section{A concepção husserliana de Psicologia antes de investigações lógicas}

Muitas vezes Husserl é apresentado como alguém que simplesmente levou adiante e desenvolveu o conceito de intencionalidade, tal como Brentano o concebera em sua Psicologia do ponto de vista empírico. Essa visão é parcialmente verdadeira. Existem importantes pontos de ruptura entre Husserl e Brentano. Para compreendermos essas rupturas é preciso olhar o histórico intelectual de Husserl. Ou seja, é de um livro, Filosofia da Aritmética, um estudo lógico e psicológico, publicado em 1891. Esta obra recebeu, no ano de 1894, uma resenha do filósofo e lógico Gottlob Frege, o qual criticava violentamente Husserl por confundir o número com a representação do número. Para Frege (1894/1972), a representação do número era algo psíquico, subjetivo e privado. Ou seja, cada pessoa tem acesso apenas às suas próprias representações. Contudo, o próprio número não tinha essas características. O número era ideal (não psíquico), objetivo (não subjetivo) e intersubjetivamente acessível (não privado).

De acordo com Frege, Husserl, por confundir o número com a representação do número, acabou cometendo uma forma de psicologismo. Ou seja, o projeto de Husserl, o de explicar a origem psicológica do conceito de número era, em si mesmo, um projeto furado, pois partia de um falso problema preciso notar que há uma diferença entre suas concepções filosóficas presentes em sua primeira obra publicada, em 1891, Filosofia da Aritmética, e suas 
concepções em sua grande obra, Investigações Lógicas, publicada em 1900/1901.

Husserl havia estudado inicialmente com Brentano, para depois, sobre a orientação de Stumpf, realizar um doutorado de habilitação sobre a origem psíquica do conceito de número. O material deste doutorado foi reunido e organizado na forma.

\section{As investigações lógicas}

Husserl, em função da crítica de Frege e da leitura de Lotze e Bolzano, adota o platonismo lógico, passando a defender a distinção entre entidades reais (naturais) e entidades ideais (números, verdades, proposições, significados, essências). É justamente essa virada ao platônico lógico ${ }^{2}$ o principal ponto que afasta Husserl de Brentano, uma vez que o platonismo afeta profundamente a teoria da intencionalidade que Husserl desenvolve em Investigações Lógicas. Podemos dizer, de maneira muito resumida, que nesta obra, Husserl pretende analisar as estruturas intencionais da consciência, com o intuito de mostrar como as entidades ideais são apreendidas pelo sujeito psíquico.

Em Investigações Lógicas, Husserl defende que a matemática e a lógica são ciências a priori que buscam obter conhecimentos a priori de entidades ideais. A matemática estuda entes ideais como figuras geométricas, planos, linhas, pontos. A lógica, em especial a lógica apofântica, estuda as estruturas formais de entidades ideais como proposições, teorias, demonstrações. Para Husserl, reduzir entidades ideais a vivências implica em psicologismo, o qual, por sua vez, implica em relativismo (Husserl, 1900). Essa é a tese que Husserl defende na primeira parte de Investigações Lógicas, publicada em 1900, os Prolegômenos a uma lógica pura. Tratava-se de um estudo preliminar para a segunda parte da obra, que foi publicada no ano seguinte, as seis Investigações Lógicas para a fenomenologia e a teoria do conhecimento. Logo no prefácio desta segunda parte da obra, Husserl (1901) deixa claro que o que ele busca é uma epistemologia capaz de legitimar o platonismo lógico defendido na primeira parte. Essa epistemologia deveria ser fundamentada em uma análise das vivências psíquicas, em especial, das vivências do conhecer. "Fenomenologia é, no essencial, psicologia descritiva. Como consequência, a crítica do conhecimento é essencialmente psicologia, ou ao menos algo que só no campo da psicologia pode edificar." (Husserl, 1901/2012, p.16).

É claro que, se em 1901 Husserl entende que a fenomenologia é uma forma de psicologia descritiva, isso significa que ele teve que adotar um critério delimitador de seu campo de estudo. Ao fazê-lo, poderíamos esperar que Husserl tenha se colocado ao lado de 
Brentano, para quem o objeto da psicologia eram os atos psíquicos. Mas não é exatamente isso o que ocorre. Em Investigações Lógicas, Husserl, sem rejeitar a ideia de que a intencionalidade constitui o traço descritivo fundamental da consciência, aceita a delimitação que Wundt ofereceu da psicologia. Para Wundt o domínio da psicologia não é circunscrito pelo conceito de intencionalidade, mas pelo conceito de vivência. Para Brentano, o objeto de estudo da psicologia são os atos. E todo ato caracteriza-se pela intencionalidade. Husserl procura conciliar essas duas posições, defendendo que, de fato, o objeto da psicologia são as vivências, as quais, pelo seu turno, dividem-se entre vivências intencionais e vivências não-intencionais. Nas vivências intencionais, estamos conscientes de um objeto transcendente à própria vivência. Isso ocorre quando imaginamos, percebemos, recordamos, criamos expectativas sobre o futuro, julgamos, nomeamos, etc. Se eu percebo um cachorro, a vivência de perceber o cachorro é parte do fluxo de minha consciência, mas o cachorro percebido, do qual eu estou consciente, é transcendente ao conteúdo real-imanente de minha consciência. O peculiar da concepção husserliana de consciência é que ela rompe com o modelo clássico, herdado da modernidade, em que ela é tida como uma espécie de caixa hermeticamente fechada, que tem acesso apenas a seus próprios conteúdos internos. Pelo contrário, o maravilhoso da consciência e, em particular, da consciência intencional, é o fato de que aquilo de que estamos conscientes não se encontra dentro da consciência. Ou seja, estamos conscientes de objetos transcendentes à própria consciência (Husserl, 1901/2012). A intencionalidade é um movimento de autotranscedência.

Mas nem todas as vivências são intencionais. É o caso, por exemplo, das vivências de náusea, sensações de dor, tontura, angústia, sensações cromáticas, etc. Se eu tenho uma sensação de vertigem, eu simplesmente tenho a sensação de vertigem. Uma vertigem não é uma vertigem a respeito de algo. Ou seja, toda vivência intencional dirige-se a um objeto intencional que lhe é transcendente, ao passo que vivências não-intencionais não têm uma referência exterior a si própria.

Finalmente, é preciso observar que, em vários casos, as vivências intencionais possuem em sua base vivências não-intencionais. Isso ocorre, por exemplo, com as vivências de percepção. Para Husserl, há uma diferença entre ter sensação e perceber algo. A percepção é uma vivência intencional, a sensação é uma vivência não-intencional. A percepção é sempre percepção de algo. Já a sensação é apenas uma vivência que pertence ao fluxo de consciência e nada mais. A princípio, seria concebível alguém ter apenas sensações e não ter nenhuma percepção Husserl (1901/2012,). Husserl afirma que a percepção é a interpretação (ou apreensão) objetivante de sensações Husserl (1901/2012). As sensações são interpretadas com um 
determinado sentido, em função do qual um objeto aparece. Uma sensação de cor vermelha, por exemplo, pode ser apreendida como a aparição de uma bola de bilhar vermelha.

Embora as vivências não-intencionais não tenham por si só um objeto a que se referem, elas pertencem, não obstante, ao campo de estudo da psicologia e, portanto, da fenomenologia. Posteriormente, Husserl irá distinguir dois campos de estudo na fenomenologia: a hilética, que examina as vivências não-intencionais, e a noética, que investiga propriamente as diferentes formas de vivências intencionais e seus os momentos constituintes Husserl (1913/1950).

\section{0 conceito de vivência em investigações lógicas}

No instante em que Husserl entende que o objeto da psicologia são as vivências, torna-se claro que ele deve apresentar uma definição rigorosa do conceito de vivência. Mais uma vez Husserl aceita a caracterização que Wundt faz das vivências:

Sob estes últimos termos de vivência e conteúdo, visa a Psicologia moderna às ocorrências reais (Wundt diz com razão: acontecimentos) que, mudando de momento para momento, em múltiplas ligações e interpenetrações, constituem a unidade real de consciência do respectivo indivíduo psíquico. (Husserl, 1901/2012, p. 296) ${ }^{3}$.

Mas como explorar a consciência e as diferentes vivências? É neste ponto que Husserl se aproxima bastante de Brentano. Husserl acreditava que o trabalho descritivo cumpre um papel central para a psicologia científica. A tarefa de descrever as vivências não substitui a de explicá-las causalmente e vice-versa. Ademais, a primeira é condição da segunda. Em Investigações Lógicas, Husserl assume que vivências, justamente por serem processos reais, estão vinculadas causalmente com os diferentes órgãos do corpo. Uma vivência é algo que ocorre integrado no organismo psicofísico, assim como a produção de bile. E assim como descrever a bile não implica em explicar suas condições causais, também a descrição das vivências não diz nada sobre suas causas naturais. Ainda assim, uma vivência é parte integrante do fluxo de consciência, que é uma parte integrante de um ser psicofísico. Em suma, embora Husserl assuma em Investigações Lógicas que haja um vínculo causal entre as vivências conscientes e o corpo físico, ele também deixa claro que não cabe à fenomenologia a investigação desse vínculo. Essa tarefa cabe à psicologia empírica e não à fenomenologia. Isso por uma razão simples: a descrição de um fenômeno, crê Husserl, nada diz sobre suas causas. Por mais que eu descreva um vulcão, não irei 
encontrar na descrição do vulcão as causas de sua formação. Por melhor que eu descreva a vivência de uma percepção, tal como ela se manifesta em primeira pessoa, não irei encontrar nada como neurônios e sinapses nervosas.

\section{A concepção de psicologia em investigações lógicas}

Para Husserl, a psicologia descritiva (ou fenomenologia) cumpre duas funções:

Servir de propedêutica à realização de uma psicologia natural-causal (ou psicologia empírica). Como afirma Husserl:

A fenomenologia pura apresenta um domínio de investigações neutras, no qual diferentes ciências encontram suas raízes. Por um lado, ela serve à preparação da Psicologia enquanto ciência empírica. Ela analisa e descreve (especialmente enquanto fenomenologia do pensar e do conhecer) as vivências representativas, judicativas e cognitivas, que devem encontrar na Psicologia a sua explicação genética e a sua investigação segundo as conexões empírico-legais. (Husserl, 1901, p. 4; 1901/2012, p. 2).

Fundamentar epistemologicamente a lógica pura, pela clarificação da origem intuitiva dos conceitos lógicos e das relações entre idealidade e vivência. Como afirma Husserl:

Por outro lado, a fenomenologia dá acesso às "fontes" de onde "brotam" os conceitos fundamentais e as leis ideais da lógica pura, fontes às quais se deve, de novo, fazê-los retornar, se quisermos obter a "clareza e distinção" que é exigível a uma compreensão crítico-gnosiológica da lógica pura. (Husserl, 2012, p. 21;1901, p. 4).

Essa primeira função, entretanto, é apenas sugerida na obra, mas não desenvolvida. Contudo, encontra-se justamente aí a razão por que a obra chamou a atenção de vários psicólogos da época, que viram na fenomenologia a consumação do projeto brentaniano de preparar a psicologia para a edificação de uma psicologia naturalcausal (Brentano, 1890/2002). Se Husserl havia realizado a parte descritiva de classificação e descrição das vivências, restava agora a próxima tarefa, a de encontrar as conexões empírico-legais. Ou seja, era hora de a psicologia explicativa entrar em cena. O que iremos examinar a seguir é justamente como várias escolas de psicologia da Alemanha, na primeira década de 1900, interpretaram as 
Investigações Lógicas como um trabalho preparatório para a realização de uma psicologia empírica e inclusive experimental.

\section{A influência de investigações lógicas nos centros de psicologia da Alemanha}

\section{a) Göttingen}

Logo após a publicação de Investigações Lógicas, Husserl, até então um desconhecido professor de Halle, alcança certa celebridade. Como resultado, ele foi convidado para lecionar na famosa universidade de Göttingen. Lá, já se encontrava o psicólogo experimental Ellias Müller. As pesquisas de Müller consistiam, em certo sentido, em um aprimoramento daquelas feitas por Ebbinghaus a respeito da memória e da aprendizagem. Contudo, diferentemente deste, Müller concluíra em suas pesquisas que a associação por contiguidade é insuficiente para explicar a aprendizagem. Para compreender a aprendizagem e a capacidade de retenção de informações era preciso levar em consideração o fato de que os sujeitos buscam ativamente as relações entre os estímulos. Daí que a assimilação depende da atitude mental do sujeito, como prontidão, hesitação, dúvida, motivação (Malone, 2009).

Não foi propriamente Müller que foi influenciado por Husserl, mas sim os seus alunos, sobretudo três nomes que posteriormente serão reconhecidos internacionalmente, Géza Révész (1878-1955), Edgar Rubin (1886-1951) e David Katz (1884-1956). Destes três autores, David Katz é particularmente importante, por ser representativo da relação que existe entre o surgimento da Gestalt e a fenomenologia husserliana.

Katz obteve seu doutorado em 1906 e no ano seguinte tornou-se docente privado em Göttingen e assistente de Müller, com quem trabalhou até 1918. Em 1911, Katz publicou sua obra mais reconhecida e original: Os modos de aparência da cor (Die Erscheinungsweisen der Farben). O próprio Katz afirma que, ao lado de Müller, ele sofrera forte influência de Husserl, de quem teve oportunidade de assistir a seminários e conferências, situação não incomum, dado que todo estudante de Müller necessariamente também deveria estudar com Husserl (Spiegelberg, 1972). Daí que vários dos alunos de Husserl serviram de sujeitos aos experimentos de Müller e, inversamente, muitos dos colaboradores deste assistiram às preleções daquele.

É importante notar que as pesquisas realizadas em Göttingen influenciaram profundamente a Gestaltpsychologie. Katz, por exemplo, é um dos primeiros gestaltistas. Sua tese doutoral Modos de aparência da cor é considerada por Köhler (1961) uma obra 
precursora da Gestalt. E não podemos esquecer que Husserl participou da banca de doutorado de Katz.

\section{b) Stumpf e a escola de Berlim}

Enquanto em Göttingen, os jovens pesquisadores eram influenciados por Husserl e Müller, o laboratório de Berlim, liderado por Stumpf, dava importantes passos na consolidação da nova ciência da psicologia. Usualmente Stumpf é mencionado nos livros de história da psicologia pelos seus estudos sobre a percepção espacial e os fenômenos acústicos, os quais ele realizou em sua monumental Psicologia do som (Tonpsychologie), cujo primeiro volume foi publicado em 1883 e o segundo em 1890. Stumpf também é mencionado por ter sido supervisor tanto de Husserl, em sua tese doutoral defendida em 1887, quanto de Wolfgang Köhler (18871967), cuja tese foi defendida em 1909. Menos comentados, mas muito influentes, foram dois tratados publicados por Stumpf em 1906, Erscheinungen und psychische Funktionen (Fenômenos e funções psíquicas) e Zur Einteilung der Wissenschaften (A classificação das ciências). Nestes dois textos, que foram amplamente discutidos na época (Fisette, 2006), Stumpf defende a distinção de Dilthey entre "ciências naturais" e "ciências do espírito", estas últimas compreendidas como ciências de funções psicológicas complexas. As ciências do espírito encontrariam seu fundamento na psicologia descritiva, que é uma ciência cujo objeto são as funções básicas psíquicas (ou os atos psíquicos) e não a matéria do ato, ou seja, os fenômenos. A ciência que estuda os fenômenos enquanto tais seria justamente a fenomenologia, a qual deveria ser entendida como uma disciplina neutra, uma vez que não é nem ciência natural, nem ciência do espírito. A cor, tal como ela se manifesta, não é nem um fenômeno psíquico, como Husserl afirma, nem um fenômeno físico, como Brentano afirma. Ora, a cor, tomada por si só, não pertence à psicologia, já que ela não é uma função psíquica, mas também não pertence à física, já que ela não é uma entidade física (como o comprimento de onda). Trata-se, portanto, de um fenômeno neutro. $O$ estudo destes fenômenos neutros teria o importante papel de propedêutica das ciências. (Fisette, 2006). É interessante observar que, em Classificação das Ciências, Stumpf faz questão de deixar claro que ele se afasta da definição de fenomenologia apresentada por Husserl em Investigações Lógicas:

Husserl prefere a expressão "fenomenologia da experiência interna" (Phänomenologie der inneren Erfahrung) para a descrição pura e simples das vivências dos atos (Akterlebnisse), utilizando o termo fenomenologia para evitar a confusão com a psicologia genética, cuja influência a respeito 
de problemas da lógica foi sentida por ele como sendo, em si, prejudicial. Aqui eu uso o termo fenomenologia em outra acepção e considero adequado manter o termo "psicologia descritiva" para a simples descrição das vivências dos atos (Akterlebnisse), que é mais adequado para essa finalidade porque, com efeito, o seu objeto de estudo, as funções psicológicas elementares, é comum tanto à psicologia descritiva quanto à psicologia genética e porque esse objeto comum corre o risco de ser obscurecido pela escolha de uma expressão completamente diferente (Stumpf, 1906/2006b, p. 35).

É preciso esclarecer, entretanto, que na ocasião da publicação deste texto, Husserl já havia se dado conta de que a definição de fenomenologia como psicologia descritiva, tal como ele apresentara em Investigações Lógicas, era inapropriada, pois não deixava claro que o que era descrito era a estrutura essencial das vivências. É importante ainda ressaltar que é justamente entre os anos 1906 e 1907 que Husserl começa a desenvolver o método da redução transcendental. Posteriormente, Husserl distinguirá, como já foi mencionado, duas formas de análises fenomenológicas: noética, que diz respeito à análise das estruturas intencionais, e hilética, que diz respeito à análise das vivências não-intencionais. Em certo sentido, o conceito de fenomenologia proposto por Stumpf coincide basicamente com o que Husserl denominava de análise hilética (Fisette, 2006).

\section{c)Wüzburg e a "Psicologia do pensamento" (Denkpsychologie)}

Embora a influência de Husserl na escola experimental de Wüzburg possa ser observada apenas a partir de 1906, ela não foi menos importante. Em 1896, junto a Karl Marbe (1868-1953), Külpe havia fundado seu laboratório de estudos experimentais. Este laboratório, mesmo construído nos moldes do laboratório de Wundt, privilegiava os processos psicológicos superiores, em especial o "pensamento". Isso contra o parecer de Wundt, de quem Külpe fora assistente em Leipzig durante 1887 a 1894. Como a psicologia de Wundt encontrava-se integrada ao seu pensamento filosófico, a expansão do objeto da psicologia experimental no laboratório de Wüzburg exigiu uma nova fundamentação filosófica. Wundt via com desconfiança o método empregado por Külpe, método esse que consistia basicamente em pedir aos sujeitos experimentais relatos retrospectivos de suas experiências cognitivas. Um dos métodos mais clássicos empregados pelos pesquisadores da Denkpsychologie foram os testes de associações de palavras. Os sujeitos eram requisitados a dizer a primeira palavra que lhes viesse à mente ao escutar a palavra proferida pelo aplicador do teste. Em seguida, eram questionados 
acerca dos nexos que eles viam entre a palavra estímulo e a palavra que emergia na consciência (Malone, 2009).

Não intimidados pelas críticas de Wundt ao método "introspectivoretrospectivo", seus membros continuaram a fazer pesquisas, dentre as quais merecem destaque as realizadas por Marbe, que constatou experimentalmente a existência de "pensamentos sem imagens", levando-o a introduzir o importante conceito de "disposições de consciência" (Bewusstseinslage), que se tornou um dos principais focos das pesquisas de Wüzburg. É nesta linha que se insere as pesquisas realizadas por Messer (1867-1937) e Bühler (1879-1963), dois jovens pesquisadores que viram nas Investigações Lógicas as ferramentas conceituais necessárias para a realização rigorosa de seus experimentos psicológicos.

Messer, que fora aluno de Wundt e Lipps, no prefácio de sua Sensação e Pensamento (Empfindung und Denken), escreve:

Um trabalho adicional, não primariamente psicológico, que trouxe muita clarificação nesta matéria, deve ser mencionado aqui: Investigações Lógicas. Esta contém muito do que há de mais importante para a psicologia do pensamento, além disso, perfaz de modo preciso e distinto a difícil tarefa de separar a abordagem psicológica da abordagem lógica ao pensamento. (Messer, 1908, p. 7).

Trata-se apenas de uma dentre as 29 citações ao nome de Husserl nesta obra.

Bühler, ex-aluno de Stumpf em Berlim, completou sua tese de habilitação em Würzburg em 1907, publicando-a pouco depois com o título Tatsachen und Probleme zu einer Psychologie der Denkvorgänge (Fatos e problemas de uma psicologia dos processos de pensamento). Aí, Bühler, usando o método por ele desenvolvido, o experimento de interrogação (Ausfrageexperimente), distinguiu certos tipos de pensamento ", dentre os quais as 'intenções' (Intentionen). A respeito desse último tipo de pensamento, Bühler declara estar de pleno acordo com Husserl em Investigações Lógicas. $\mathrm{E}$, se Bühler aproxima-se de Husserl, por outro lado, não poupa ataques a Wundt:

De acordo com Wundt, é quase uma exigência psicológica que cada ato de pensamento tem de ser representado em nossa consciência sob a forma de certas apresentações individuais. Mas nossos métodos demonstram que este teorema está completamente errado. Há sim pensamentos sem qualquer traço de imagens. (Bühler, 1908, p. 318). 


\section{Wundt e as investigações lógicas}

Os ataques que os componentes da Denkpsychologie fizeram a Wundt não permaneceram sem resposta. Neste mesmo ano de 1908, o veterano Wundt parte para o contra-ataque, escrevendo em sua revista um artigo de 66 páginas, intitulado Sobre o Experimento de Interrogação e sobre os métodos para a psicologia do pensamento (Über Ausfrageexperimente und über die Methoden zur Psychologie des Denkens). Neste ensaio, Wundt procura demonstrar como os resultados obtidos por métodos falsos, como Ausfrageexperimente, são destituídos de valor científico. E ainda insiste, no mesmo ensaio, o que já vinha afirmando desde 1883: os processos superiores de pensamento não podem ser abordados com 0 uso da experimentação. ${ }^{5}$ Iniciada a forte polêmica contra a escola experimental de Wüzburg, o próximo passo de Wundt foi atacar a obra na qual o grupo vinha se escorando, as Investigações Lógicas. Em artigo publicado em 1910, Psicologismo e Logicismo (Psychologismus und Logizismus), Wundt, filiando Husserl à escola de Brentano, acusa ambos de defenderem formas de logicismo.

Ainda mais estranho do que o fracasso do psicologismo é o fato de que o logicismo [i.e. a posição defendida por Brentano e Husserl] não conduz a nada melhor. O último não é bem sucedido apesar de enfaticamente apelar para a evidência das leis lógicas. Isso ocorre porque o apelo logicista [para a autoevidência das leis lógicas] se move em um círculo contínuo: ele declara as leis lógicas autoevidentes, mas então fundamenta a autoevidência sobre a validade das leis lógicas. Para escapar desse círculo, o logicismo não pode fazer nada melhor do que declarar que a autoevidência é um fato último e que não pode mais ser definida (Wundt, 1910, p. 623).

O quão profundamente Husserl ficou irritado com as críticas de Wundt pode ser observado em um novo prefácio que Husserl preparou em 1913 para a segunda edição de Investigações Lógicas, mas que foi publicado apenas postumamente ${ }^{6}$. Em seu texto, Husserl afirma que Wundt entendera mal as Investigações Lógicas, que não há ali uma defesa do logicismo, que apenas a cegueira intelectual poderia levar alguém a querer refutar o valor da evidência. Mas, no que concerne à acusação feita por Wundt a respeito de que ele buscava uma reforma da psicologia, Husserl (1913/2002) acaba assumindo:

E mesmo se o volume das Investigações lógicas não tem uma única palavra programática a esse respeito, mas sim uma abordagem frontal a alguns dos problemas fundamentais 
relacionados ao pensamento lógico e seus correlatos, propiciando peças para um desenvolvimento de trabalho, é de fato inegável que o que é feito lá também concerne essencialmente à psicologia e, se correto, prepara novos métodos para lidar com problemas psicológicos e, assim, realmente, como diz Wundt, implica uma reforma da "psicologia" (Husserl, 1913/2002, p. 318).

Neste texto, Husserl menciona que, embora "alguns jovens pesquisadores tenham percebido a relevância das Investigações Lógicas para os problemas da psicologia", (1913/2002, p. 318) da antiga geração de scholars apenas Dilthey e Wundt (apesar dos equívocos deste último) a notaram. É muito provável que dentre estes jovens pesquisadores estejam aqueles de Wüzburg e de Göttingen.

\section{Conclusão}

Ao longo deste artigo, pudemos observar que a obra Investigações Lógicas foi recepcionada por uma série de pesquisadores na primeira década do século XX como tendo, dentre outros objetivos, o de embasar a psicologia empírica. Ou seja, a obra foi recepcionada, até 1911, quando Husserl publica Filosofia como ciência de rigor, como uma obra de psicognose, a qual levava a cabo o projeto brentaniano. Essa recepção fundamenta-se em uma base textual. Em primeiro lugar, Husserl define a fenomenologia como psicologia descritiva. Vimos que Stumpf, em 1906, critica justamente essa concepção em Husserl, a qual considera inapropriada. Em segundo lugar, Husserl afirma, em 1901, que, embora não caiba à fenomenologia estabelecer as ligações de regularidades empíricas entre os fenômenos psíquicos, essas regularidades permanecem pressupostas. De fato, Husserl admite, em 1901, que vivências são eventos pertencentes ao nexo global da natureza. $\mathrm{Na}$ época, ele julgava que toda vivência é uma vivência psíquica. E toda vivência psíquica é um processo plenamente integrado causalmente no todo psicofísico do organismo (Husserl, 1901/2012). Daí que toda vez que uma vivência ocorre, ela ocorre porque determinadas condições causais ocorreram.

Dada essa situação, é perfeitamente compreensível a razão por que vários pesquisadores se apoiaram na fenomenologia de Investigações Lógicas a fim de estabelecer seus respectivos programas de pesquisa. Particularmente importante é a tentativa de vários pesquisadores da escola de Wüzburg de buscar nas Investigações Lógicas o fundamento epistemológico da Denkpsychologie. Husserl havia, em Prolegômenos, distinguido com precisão a vivência de 
pensar, do conteúdo pensado, argumentando que a confusão entre ambos implica o psicologismo. Foi essa distinção que pareceu central para vários autores da escola de Wüzburg, particularmente a Messer, que deixa claro, em sua tese de 1908, Sensação e Pensamento, que ele pretende estudar a vivência de pensar, e não a estrutura lógicoideal do conteúdo objetivo das vivências de pensar. A ideia de Messer, assim como a de outros membros da escola de Wüzburg, é que seria possível realizar uma psicologia empírica dos processos psíquicos de pensar sem recair no psicologismo.

Pudemos observar que Husserl também exerceu influência na psicologia experimental realizada em Göttingen, sobretudo nos discípulos de Ellias Müller, em particular David Katz, cuja tese de doutorado, Os modos de aparência da cor, pode ser considerada uma fenomenologia da experiência das cores.

Finalmente, devemos lembrar que a concepção de fenomenologia não era algo exclusivo de Husserl. Havia várias outras propostas de fenomenologia competindo com aquela que Husserl apresentara em Investigações Lógicas. Stumpf, por exemplo, empregava o termo para designar a investigação do conteúdo das funções psíquicas. E em 1900, o psicólogo da escola de Munique, Alexander Pfänder, já havia escrito um livro intitulado Fenomenologia da vontade (Phänomenologie des Wollens), para designar uma forma de psicologia descritiva. Mesmo se observarmos o desenvolvimento do pensamento de Husserl, podemos constatar que o termo fenomenologia foi empregado de diferentes formas. Em 1901, ele o empregava para designar uma forma de psicologia descritiva, a qual, mais tarde, ele iria caracterizar de psicologia eidética ou psicologia fenomenológica (Husserl, 1925/1962). A partir da escrita de Ideias I, ele empregará o termo fenomenologia preferencialmente para designar não uma forma psicologia, mas de filosofia transcendental (Husserl, 1913/1950). Esta última não estuda a consciência em sua apreensão mundana, ou seja, como uma psique, mas sim a "consciência 'pura', ou seja, a consciência do ponto de vista fenomenológico" (Husserl, 1911/1987, p.17).

Essa concepção aparece no artigo publicado na revista Logos "Filosofia como ciência rigorosa" (Philosophie als strenge Wissenschaft). Neste artigo ele defende que a fenomenologia é "uma ciência da consciência (Wissenschaft vom Bewußtsein) que, ainda assim, não é psicologia, mas uma fenomenologia da consciência em oposição a uma ciência natural sobre a consciência." (Husserl, 1911/1987, p.17). Ao contrário do que fez em Investigações Lógicas, Husserl não pressupõe, nesta obra, que a consciência é "um ser empírico no conjunto da natureza" (Husserl, 1911/1987, p.17). Com a virada transcendental, ele passa a entender que, embora em Investigações Lógicas ele considerasse que a fenomenologia era uma ciência neutra, ele, não obstante, acabou pressupondo a validade da 
visão naturalística do mundo (Husserl, 1925/1962). É claro que, no momento que Husserl passa a considerar a fenomenologia, em seu sentido mais autêntico, uma filosofia transcendental, a sua relação com a psicologia empírica também se modifica.

Mas isso não significa que Husserl não pensasse em estabelecer uma relação positiva com a psicologia. Husserl nunca abandonou a ideia de que a fenomenologia pode contribuir para a psicologia empírica, ao clarificar os conceitos dessa última. E a fenomenologia, tomada como psicologia fenomenológica, possui um importante papel para a realização da psicologia empírica, como ele defende explicitamente em seu artigo para a Enciclopédia Britânica: "a psicologia fenomenológica é uma disciplina apriorística, apta a fornecer a única base segura sobre a qual uma psicologia empírica pode ser construída" (Husserl, 1925/1962, p.278).

\section{Discussão final}

Tivemos a oportunidade de observar que, na primeira metade do século XX, houve uma forte relação entre a fenomenologia de Husserl e a psicologia empírica (genético-causal). Vários pesquisadores tomaram Investigações Lógicas como uma obra de psicologia descritiva, razão pela qual ela serviu de inspiração para a elaboração de experimentos psicológicos. Essa mesma forma de relação se repete agora, depois de quase um século. É cada vez maior a aproximação entre a fenomenologia e as ciências cognitivas (Schmicking \& Gallagher, 2010), bem como entre fenomenologia e neurosciências (2010; Petitot, Varela, Pachoud, \& Roy, 2000; Gallese, 2006). Essa aproximação ocorreu pela retomada, sobretudo nos últimos trinta anos, do tema da consciência por autores ligados às neurociências, à psicologia cognitiva, à filosofia da mente e mesmo à filosofia analítica. Essa retomada do problema da consciência, ou daquilo que na tradição de língua inglesa se passou a chamar phenomenal self, começou devido a uma série de fatores. Gallagher e Zahavi (2012) apresentam vários motivos para essa retomada, dentre os quais dois merecem destaque. Em primeiro lugar, o aperfeiçoamento de técnicas não invasivas de mapeamento cerebral tem exigido relatos da experiência consciente, realizados em primeira pessoa, cada vez mais precisos. Isso porque o objetivo de vários pesquisadores não é apenas entender o que se passa no cérebro do ponto de vista físico-químico, mas sim a relação entre o que se passa no cérebro e a experiência consciente. $O$ segundo fator repousa na constatação das limitações do comportamentalismo e de uma psicologia cognitiva inspirada no funcionalismo, que trata a consciência como um software apto a processar informações e, deste 
modo, passa por alto a dimensão fenomênica da consciência (Simanke, 2012).

Com o problema da consciência entrando na pauta do dia, começaram a surgir propostas de resgatar a psicologia fenomenológica husserliana, já que esta não negava a psicologia empírica mas, pelo contrário, buscava uma relação positiva com esta última. Husserl defendia que a realização da psicologia empírica dependia de uma descrição adequada dos fenômenos, realizada em primeira pessoa. Essa descrição deveria inclusive preceder epistemologicamente discussões metafísicas sobre a consciência, como, por exemplo, discussões sobre sua redutibilidade ou irredutibilidade à sua base material-cerebral.

Como tivemos a oportunidade de observar, a ideia de Husserl de que a psicologia depende de uma descrição da consciência realizada em primeira pessoa permanece viva, assim como esteve viva na primeira década do século XX. Neste artigo, apenas indicamos a existência histórica desta relação entre fenomenologia e ciências empíricas. Contudo, cremos que um conhecimento aprofundado destas escolas pode servir para o esclarecimento de questões atuais, referentes à relação entre fenomenologia e ciências empíricas.

\section{Referências}

Araujo, S. D. F. (2010). Projeto de uma psicologia científica em Wilhelm Wundt: uma nova interpretação. Juiz de Fora: UFJ F.

Araújo, S. D. F. (2013). O Manifesto dos filósofos alemães contra a psicologia experimental: introdução, tradução e comentários. Estudos e pesquisas em psicologia, 13(1), 298-311.

Brentano, F. C. (1874). Psychologie vom empirischen Standpunkt. Leipzig: Verlag von Duncker \& Humblot.

Bühler, K. (1907). Tatsachen und Probleme zu einer Psychologie der Denkvorgänge. I. Uber Gedanken. Habilitationsschrift... von Karl Bühler. Leipzig: W. Engelmann.

Caputto, M. (Ed.). (2006). Neurofenomenologia: le scienze della mente e la sfida dell'esperienza cosciente: B. Mondadori.

Fisette, D. (2006). La philosophie de Carl Stumpf, ses origines et sa postérité.

Frege, G. (1972). Review of Dr. E. Husserl's Philosophy of Arithmetic. Mind: New Series, 81(323), 321-337. (Trabalho original publicado em 1894)

Gallagher, S., \& Zahavi, D. (2012). The phenomenological mind (2nd ed.). Abingdon, Oxon: New York: Routledge.

Gallese, V. (2006). Corpo vivo, simulazione incarnata, intersoggettività. Una prospettiva neuro-fenomenologica, in Neurofenomenologia. In M. Cappuccio (Ed.), 
Neurofenomenologia. Le scienze della mente e la sfida dell'esperienza cosciente (pp. 293-326). Milano: Bruno Mondadori Editore.

Gundlach, H. (2012). A Psicologia como ciência e como disciplina: o caso da Alemanha. In S. d. F. Araujo (Ed.), História e filosofia da psicologia: perspectivas contemporâneas. Juiz de Fora: UFJF.

Husserl, E. (1891). Philosophie der Arithmetik. Psychologische und logische Untersuchungen. Halle-Saale: C. E. M. Pfeffer. (Trabalho original publicado em 1891).

Husserl, E. (1900). Logische Untersuchungen 1: Prolegomena zur reinen Logik. Halle a/S.: Niemeyer

Husserl, E. (1901). Logische Untersuchungen 2: Untersuchungen zur Phänomenologie und Theorie der Erkenntnis. Halle: Niemeyer.

Husserl, E. (1952). Ideen zu einer reinen Phänomenologie und phänomenologischen Philosophie; Buch 2, Phänomenologische Untersuchungen zur Konstitution. Den Haag: Nijhoff

Husserl, E. (1962). Phänomenologische Psychologie: Vorlesungen Sommersemester 1925. Haag: Martinus Nijhoff. (Manuscrito original de 1925. Publicação póstuma de 1962).

Husserl, E. (1987). Aufsätze und Vorträge: 1911-1921. Dordrecht, Boston: M. Nijhoff. (Trabalhos e manuscritos do período de 1890-1910).

Husserl, Edmund. (2012). Investigações lógicas. Segundo Volume. Parte I, Investigações para a fenomenologia e a teoria do conhecimento (P. M. S. Alves \& C. A. Morujão, Trans. Vol.

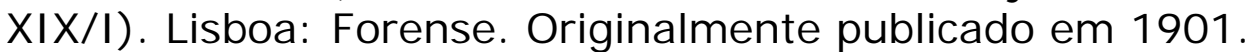

Husserl, E. (2002). Logische Untersuchungen: Ergänzungsband (U. Melle Ed.). Dordrecht [etc.]: Kluwer Academic Publishers. (Trabalhos originais compreendidos entre 1900-1913).

Husserl, E. (2012). Investigações lógicas. Segundo Volume. Parte I, Investigações para a fenomenologia e a teoria do conhecimento (P. M. S. Alves \& C. A. Morujão, Trans. Vol. XIX/I). Lisboa: Forense. Originalmente publicado em 1900.

Katz, D. (1911). Die Erscheinungsweisen der Farben und ihre Beeinflussung durch die individuelle Erfahrung. Leipzig,: J. A. Barth.

Katz, D. (1950). Gestalt psychology; its nature and significance. New York: Ronald.

Köhler, W. (1961). Gestalt psychology Today. In M. Henle (Ed.), Documents of Gestalt psychology (pp. 1-15). Berkeley: University of California Press.

Kusch, M. (1995). Psychologism : a case study in the sociology of philosophical knowledge. London; New York: Routledge.

Malone, J. C. (2009). Psychology: Pythagoras to Present: The MIT Press. 
Messer, A. (1908). Empfindung und Denken. Leipzig: Quelle \& Meyer.

Peres, S. P. (2014). O problema da transcendência do objeto da percepção $E$ do objeto da física nas investigações lógicas de Husserl. Philósophos - Revista de Filosofia, 19(1), 219-246.

Petitot, J., Varela, F., Pachoud, B., \& Roy, J. M. (2000). Naturalizing Phenomenology: Issues in Contemporary Phenomenology and Cognitive Science. Stanford: Stanford University Press.

Pfänder, A. (1900). Phänomenologie des Wollens; eine psychologische Analyse. Leipzig: J. A. Barth.

Schmicking, D., \& Gallagher, S. (Eds.). (2010). Handbook of phenomenology and cognitive science. Dordrecht, London: Springer

Smith, R. (2012). A História da Psicologia tem um objeto? In Araujo, S. F. (Ed.) História e filosofia da psicologia: perspectivas contemporâneas (pp. 15-56). Juiz de Fora: UFJF.

Smith, R. (2012). A História da Psicologia tem um objeto? In S. d. F. Araujo (Ed.), História e filosofia da psicologia: perspectivas contemporâneas (pp. 15-56). Juiz de Fora: UFJF

Stumpf, C. (2006a). De la Classification des Sciences (D. Fisette, Trans.). In D. Fisette (Ed.), La philosophie de Carl Stumpf, ses origines et sa postérité (pp. 169-254).

Stumpf, C. (2006b). Phénomènes et Fonctions Psychiques (D. Fisette, Trans.). In D. Fisette (Ed.), La philosophie de Carl Stumpf, ses origines et sa postérité (pp. 133-167).

Wundt, W. (1910). Psychologismus und Logizismus Kleine Schriften, vol. 1 (pp. 511-634). Leipzig: Engelma.

Zahavi, D. (2003). Husserl's phenomenology. Stanford, California: Stanford University Press.

\section{Endereço para correspondência}

Sávio Passafaro Peres

Pontifícia Univerisdade Católica de São Paulo

Rua Ministro Godoi, 969, 4 andar, Bloco A, Sala 4E-16, Perdizes, CEP 05015-901, São Paulo - SP, Brasil

Endereço eletrônico: savioperes@yahoo.com.br

Recebido em: 05/05/2015

Reformulado em: 13/06/2015

Aceito para publicação em: 20/08/2015

\section{Notas}

* Pós-doutorado da Pontifícia Universidade Católica de São Paulo - Departamento de Filosofia.

${ }^{1}$ É verdade que Dilthey também exerceu uma importante influência em Husserl, mas essa influência é apenas posterior (Peres, 2014).

2 O platonismo lógico, é preciso observar, não pode ser confundido com o platonismo ontológico. Husserl não defende a existência de ideias em um mundo supranatural. O que ele defende é a validade de entidades lógico-ideais. (Zahavi, 2003, p.9). 
${ }^{3}$ Dada a importância da citação, apresento o trecho em alemão, de acordo com a primeira edição: “Unter diesen letzteren Titeln Erlebnis und Inhalt meint der moderne Psychologe die realen Vorkommnisse (Wundt sagt mit Recht: Ereignisse), welche von Moment zu Moment wechselnd, in mannigfacher Verknüpfung und Durchdringung die reale Bewufstseinseinheit des jeweiligen psychischen Individuums constituírem". (Husserl, 1901, p. 326)

${ }^{4}$ Outros tipos de pensamento: a) Regelbewußtsein (consciência de uma regra), b) Beziehungsbewußtsein (consciência de relação), c) The Aha-Erlebnis (vivência do "a-há", ou em inglês "eureka effect") d) Erinnerungserlebnis (vivência do lembrar).

${ }^{5}$ Tarefa essa que caberia à psicologia dos povos (Völkerpsychologie). I sso por três razões centrais: 1) O método experimental supõe o controle rigoroso das variáveis e das condições na qual o fenômeno é produzido. E, no caso do pensamento, não é possível controlar essas variáveis experimentalmente. 2) Os processos superiores pressupõem fatores étnicos, linguísticos e culturais do sujeito. 3) O uso da percepção interior, quando o que está em pauta são os processos superiores, afeta o curso do próprio pensamento.

${ }^{6}$ O prefácio escrito em 1913 para as Investigações Lógicas foi apenas publicado por Fink em 1939. Contudo, as seis páginas inteiramente dedicadas à polêmica com Wundt foram cortadas por Eugen Fink, por considerá-las destituídas de interesse filosófico. 